\title{
Papers
}

\section{Association of driver air bags with driver fatality: a matched cohort study}

\author{
Peter Cummings, Barbara McKnight, Frederick P Rivara, David C Grossman
}

\begin{abstract}
Objective To estimate the association of driver air bag presence with driver fatality in road traffic crashes.

Design Matched pair cohort study.

Setting All passenger vehicle crashes in the United States during 1990-2000 inclusive.

Subjects 51031 driver-passenger pairs in the same vehicle.

Main outcome measures Relative risk of death within 30 days of a crash.

Results Drivers with an air bag were less likely to die than drivers without an air bag (adjusted relative risk $0.92(95 \%$ confidence interval 0.88 to 0.96$))$. This estimate was nearly the same whether drivers wore a seat belt (adjusted relative risk 0.93 ) or not (0.91). Air bags were associated with more protection for women (0.88 (0.82 to 0.93$))$, than for men (0.94 (0.90 to 0.99$))$. Drivers wearing a seat belt were less likely to die than unbelted drivers (0.35 (0.33 to 0.36)). Belted drivers with an air bag were less likely to die than unbelted drivers without an air bag (0.32 (0.30 to 0.34$)$ ).

Conclusions If the associations are causal the average risk of driver death was reduced $8 \%$ (95\% confidence interval $4 \%$ to $12 \%$ ) by an air bag. Benefit was similar for belted and unbelted drivers and was slightly greater for women. However, seat belts offered much more protection than air bags.
\end{abstract}

\section{Introduction}

A few studies have estimated that air bags reduce the risk of driver death in a road traffic crash by $10-14 \%,{ }^{12}$ but these studies have limitations. Firstly, studies using a proportional mortality design rest on the unproved assumption that air bags are not associated with death in non-frontal crashes. $^{34}$ Secondly, most of the estimates have not been adjusted for potential confounders. Thirdly, sample size has been relatively small for some subgroups, leaving uncertainty as to whether any effect of air bags might vary.

We undertook a study of driver air bags, to estimate their influence on death in all crashes, and to estimate whether any effect varied by driver's age, sex, or seat belt use. Unlike those of previous studies, our methods allowed us to examine effect modification (statistical interaction). ${ }^{5}$

\begin{abstract}
Methods
We used a matched pair cohort design, which uses information from drivers and passengers in the same vehicle. $^{5}$ The Fatality Analysis Reporting System (FARS), a database maintained by the US National Highway Traffic Safety Administration, contains information about all crashes on US public roads that result in a death within 30 days. ${ }^{6}$ We selected records for passenger vehicles that crashed during 1990-2000 inclusive and were from model years 1987-2002. Air bags were rare in cars before model year 1987. A matched pair cohort study requires only information about those pairs in which at least one member had the outcome of interest. ${ }^{3578}$ We therefore selected records for drivers with a passenger in the right front seat in which the driver or passenger, or both, died. Vehicles with more than two people in the front were excluded. Since children were rarely drivers and we wished to control for confounding by age, we selected records for paired occupants who were both at least 16 years old. Because information about air bags is often missing in FARS data, we used the vehicle identification number and a computer program that can determine from that number whether driver and passenger air bags were present. $^{9}$

This selection process resulted in a file of driver-passenger pairs in 59121 vehicles. We then sequentially eliminated vehicles in this order: (a) 574 vehicles from any US state and year for which $25 \%$ of records were missing information about vehicle occupants' use of seat belts, (b) 23 vehicles for which the vehicle identification number indicated a model year before 1987, (c) 1020 vehicles without information on presence of air bags (usually because the vehicle identification number was missing), (d) 21 vehicles for which FARS data coded an air bag as disabled, $(e) 129$ vehicles missing information about occupants' sex, (f) 511 vehicles missing information about occupants' age, and $(g)$ 5812 vehicles missing information about seat belt use.
\end{abstract}

\section{Statistical analysis}

We estimated the relative risk of death for drivers with an air bag compared with those without, using conditional Poisson regression, a method suitable for generating relative risks from matched pair cohort data. ${ }^{5}$ Age was expressed as age and age squared; categorical transformations or quadratic splines did not appreciably change any relative risk estimates. ${ }^{11}$

\author{
Harborview Injury \\ Prevention and \\ Research Center, \\ 325 Ninth Avenue, \\ Box 359960, Seattle, \\ WA 98104-2499, \\ USA \\ Peter Cummings \\ associate professor \\ Frederick P Rivara \\ professor \\ David C Grossman \\ professor \\ Department of \\ Biostatistics, School \\ of Public Health \\ and Community \\ Medicine, \\ University of \\ Washington, Seattle, \\ WA, USA \\ Barbara McKnight \\ professor \\ Correspondence to: \\ P Cummings \\ peterc@ \\ u.washington.edu
}

BMJ 2002;324:1119-22

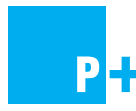

A table comparing the results with those of previous studies appears on bmj.com 
Drivers with an air bag were often paired with passengers without an air bag; but no vehicles had a passenger air bag and no driver air bag. Within pairs with a driver air bag and no passenger air bag, a relative risk estimate for air bag effects includes any effect of being in the driver seat position compared with being in the passenger seat position. We therefore used the pairs for which there were no air bags and pairs for which both had air bags to determine the effect of seat position. We then adjusted for the effect of seat position in all models. We always included interaction terms between seat position and age, sex, seat belt use, and air bag presence, as well as other interaction terms when necessary, to account for possible differences in the effect of seat position between vehicles with only a driver air bag and vehicles with both driver and passenger air bags or with neither.

We assessed whether our estimates of the effect of air bags were modified by driver's age, sex, and seat belt use or by vehicle speed, type (passenger car, van, or pickup or sport utility vehicle), weight, wheelbase, and model year or by direction of principal impact. Since speed was missing for $49 \%$ of the vehicles, we also assessed the interaction with speed limit, which was known for $99 \%$ of the records. In estimating effects by driver age, we omitted 848 vehicles with an occupant older than 90 years so that a few very old people would not influence the estimates. We used the likelihood ratio test to evaluate statistical interaction. ${ }^{12}$ We used Stata statistical software. ${ }^{13}$ The study used publicly available data without identifiers and was therefore exempted from ethical approval.

\section{Results}

The final study sample consisted of 51031 driverpassenger pairs in 32388 vehicles $(63 \%)$ with no air bags, 10126 vehicles (20\%) with air bags for driver and passenger, and 8517 vehicles (17\%) with a driver air bag only. The 8517 vehicles with only a driver air bag were usually passenger cars $(75 \%)$, with some light pickups and sport utility vehicles (17\%) and vans $(8 \%)$. Most $(66 \%)$ of these vehicles were from model years 1991-4. In these vehicles, there was little difference in the distribution of driver's age by air bag status (table 1 ), but those with an air bag were more often men (as men were more often drivers), somewhat more likely to be belted, and more likely to survive.

The adjusted relative risk of death among drivers with an air bag, compared with drivers without an air bag, was 0.92 (table 2). A test showed that this association was modified by seat belt use $(\mathrm{P}=0.03)$, but the relative risk estimates for unbelted and belted drivers were quite similar. The relative risk associated with air bags also depended on sex ( $\mathrm{P}=0.01)$; among women drivers, air bags were associated with a $12 \%$ decrease in the risk of death, whereas for men the decrease was $6 \%$. The effects of air bags were also modified by driver age $(\mathrm{P}=0.02)$, and the three way interaction between age, sex, and air bags was significant $(\mathrm{P}<0.001)$. In younger adults, the association of air bags with death was about the same for men and women (see figure). The association between air bags and death was about the same for men of all ages, but, at ages > $>50$ years, air bags were associated with more protection for women than for men.
Table 1 Characteristics of drivers with air bags and passengers without air bags in the same vehicle in fatal road vehicle crashes in the United States, 1990-2000

\begin{tabular}{lcc} 
Characteristic & $\begin{array}{c}\text { No }(\%) \text { of drivers } \\
\text { with air bag } \\
(\mathbf{n}=\mathbf{8 5 1 7})\end{array}$ & $\begin{array}{c}\text { No }(\%) \text { of passengers } \\
\text { without air bag } \\
(\mathbf{n}=\mathbf{8 5 1 7})\end{array}$ \\
\hline Age (years): & & \\
\hline $16-19$ & $1157(14)$ & $1328(16)$ \\
\hline $20-29$ & $2089(25)$ & $1993(23)$ \\
\hline $30-59$ & $2703(32)$ & $2505(29)$ \\
\hline$\geqslant 60$ & $2568(30)$ & $2691(32)$ \\
\hline Male & $5899(69)$ & $3807(45)$ \\
\hline Wore seat belt & $4823(57)$ & $4542(53)$ \\
\hline Outcome: & & $135(2)$ \\
\hline No injury & $217(3)$ & $1202(14)$ \\
\hline Minor injury & $1738(20)$ & $1686(20)$ \\
\hline Serious injury & $2088(25)$ & $5496(65)$ \\
\hline Died & $4474(53)$ & \\
\hline
\end{tabular}

Table 2 Relative risk of death for drivers with an air bag compared with drivers without an air bag in fatal road vehicle crashes in the United States, 1990-2000. (All estimates account for matching within vehicle and are adjusted for age, age squared, seat belt use, and seat position as described in the methods)

\begin{tabular}{ll} 
Group & Relative risk $(\mathbf{9 5} \% \mathbf{C l})$ \\
\hline All drivers & $0.92(0.88$ to 0.96$)$ \\
\hline Unbelted drivers & $0.91(0.85$ to 0.97$)$ \\
\hline Belted drivers & $0.93(0.88$ to 0.99$)$ \\
\hline Women drivers & $0.88(0.82$ to 0.93$)$ \\
\hline Men drivers & $0.94(0.90$ to 0.99$)$ \\
\hline Frontal crashes* & $0.84(0.79$ to 0.90$)$ \\
\hline Non-frontal crashes $\dagger$ & $1.03(0.96$ to 1.11$)$ \\
\hline Head-on crashes $\neq$ & $0.78(0.72$ to 0.85$)$ \\
\hline
\end{tabular}

*Principal impact angle at 10 o'clock to 2 o'clock.

†All crashes not frontal.

†Principal impact angle at 12 o'clock and no rollover.

Air bags were associated with a decreased risk of driver death in frontal crashes (principal impact angle from 10 o'clock to 2 o'clock) (relative risk 0.84 ) and in head-on crashes (12 o'clock principal impact and no rollover) (relative risk 0.78), but not in non-frontal crashes (relative risk 1.03) (table 2).

Our estimates might be biased if there were substantial misclassification of seat belt use. However, when we omitted seat belt information from the regression model the estimate of the association between air bag exposure and death was essentially unchanged (relative risk 0.92 (95\% confidence interval 0.87 to 0.96$)$ ). By model year 1998 , many new US cars had air bags with lower inflation pressures. ${ }^{14}$ When we omitted vehicles from model years 1998 onwards from the analysis the plot of relative risk estimates in the figure was essentially unchanged.

There was little evidence that the association of air bags with death was modified by estimated vehicle speed $(\mathrm{P}=0.7)$, local speed limit $(\mathrm{P}=0.4)$, vehicle type (passenger car, van, or pickup or sport utility vehicle) $(\mathrm{P}=0.7)$, model year $(\mathrm{P}=0.2)$, vehicle weight $(\mathrm{P}=0.5)$, or vehicle wheel base $(\mathrm{P}=0.3)$.

The relative risk of death for drivers who were belted, compared with unbelted drivers, was 0.35 (0.33 to 0.36 ). This estimate was adjusted for age, sex, and air bag presence. For drivers who were belted and had an air bag, the adjusted relative risk of death, compared with drivers who were unbelted and without an air bag, was 0.32 (0.30 to 0.34 ). 


\section{Discussion}

On average, risk of death was $8 \%(4 \%$ to $12 \%)$ lower among drivers exposed to an air bag compared with other drivers. This protective estimate was essentially the same for drivers who wore seat belts and drivers who were unbelted. Overall, air bags provided more protection to women; this difference in effectiveness by sex was primarily among older drivers.

\section{Potential limitations of study}

In a study of air bags, seat belt use may be a confounder. Information on belt use in the Fatality Analysis Reporting System (FARS) sometimes comes from observations by the police or rescue workers, but it may come from surviving occupants. Survivors might claim to be belted when they were not, as most states have penalties for failure to wear a seat belt. ${ }^{25}$ However, most survivors in our sample were classified as being seriously injured, over $95 \%$ were judged to have some injury, and all were seated next to someone who was dead or dying. These survivors may not have a great deal of concern about seat belt fines, and in many cases rescuers might have observed actual belt use. In a recent study of seat belts, two of us reported little difference in estimated relative risks of death associated with seat belt use according to whether or not a state had a penalty for not wearing seat belts. ${ }^{15}$ Furthermore, seat belt use was not associated with air bag presence, and we therefore found little confounding influence of seat belts in our analysis.

Our estimates could be biased if records with missing information differed systematically from those with recorded information. Important data, chiefly about seat belts, were missing for $8090(13.7 \%)$ potential study vehicles. Since we found little evidence that seat belt use was a confounder, we added the 5812 vehicles with missing information about belt use to the 51031 vehicles in our main analysis. These 56843 vehicles represented $96 \%$ of all vehicles eligible for this study; the estimate of average air bag effect, adjusted for age and sex but not belt use, was 0.92 in this larger sample, unchanged from our estimate of 0.92 in table 2 .

We used a matched pair cohort design. Since the people being compared were in the same vehicle, this tends to reduce potential confounding by vehicle or crash characteristics. ${ }^{5}$ However, confounding bias could still arise if a variable modified the effects of seat position and was associated with air bag presence. ${ }^{5} \mathrm{We}$ found virtually no evidence of such a bias when we allowed the effect of seat position to vary by vehicle's model year, wheelbase, weight, or type or speed limit or principal impact angle.

This was a study of a population that crashed. Therefore, our analysis cannot address the question of whether air bags are associated with the risk of crashing.

\section{Comparison with other studies}

Although our method required information only from driver-passenger pairs in which at least one died, the results apply to all driver-passenger pairs. ${ }^{35}$ Because we used a regression method suitable for matched pair cohort data, it was relatively easy for us to control for confounding or examine effect modification by age, sex, or seat belt use compared with the methods used in previous studies.

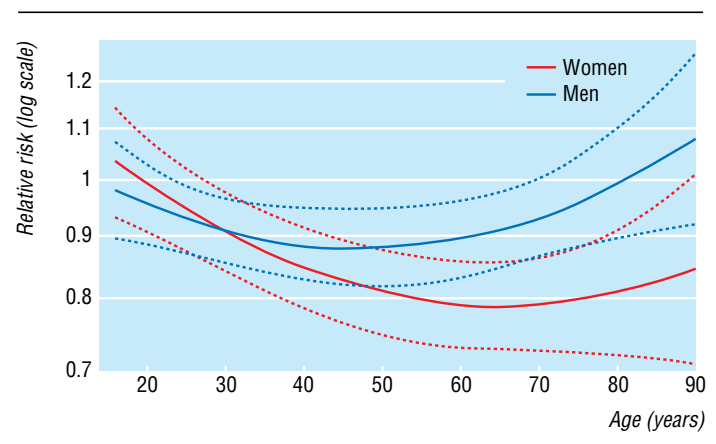

Adjusted relative risk estimates for death of a driver in a vehicle with an air bag, compared with a driver without an air bag, according to driver's age and sex (Dashed lines show pointwise 95\% confidence intervals)

Studies from the Insurance Institute for Highway Safety, summarised by Ferguson and colleagues, used a proportional mortality design. ${ }^{16}{ }^{17}$ The same design was included in a report by Kahane. ${ }^{2}$ This design may be thought of as a case-control study in which the cases are dead drivers in frontal crashes. The ideal controls would be a sample of drivers who survived a crash; instead, the design uses the air bag exposure of dead drivers in non-frontal crashes to represent the air bag exposure of surviving drivers. ${ }^{3}{ }^{4}$ The analysis can then control for potential confounding by driver age and seat belt use and vehicle weight; none of the published proportional-mortality studies has done this.

Kahane also analysed data using a type of matched pair cohort method, the double pair method published by Evans. ${ }^{257}$ This method can produce unbiased estimates in some circumstances, but it has limited ability to control for confounding or to examine effect modification. ${ }^{5}$

The relative risk of death among drivers with an air bag, compared to drivers without an air bag, ranged from 0.86 to 0.90 in previous studies, ${ }^{12}$ similar to our estimate of 0.92 (see extra table on bmj.com for details). Ferguson et al reported that air bags provided more protection to unbelted drivers but gave no evidence that this difference was significant. ${ }^{1}$ Kahane reported conflicting results-finding air bags to be more beneficial to unbelted drivers with a proportional-mortality design but less beneficial with the matched pair design. ${ }^{2}$ We found little difference in the effect of air bags according to driver's seat belt use. Unlike previous studies, our estimation method used data not only from the pairs that were both belted and pairs that were both unbelted, but also the driverpassenger pairs that differed in belt use.

Kahane reported that men may receive more benefit from air bags than women. ${ }^{2}$ We found the opposite, which surprised us. There have been a few reports of short women being killed by driver air bags, ${ }^{18}$ leading to concern that women, especially short women, may benefit less from an air bag. If the associations we report are causal it may be that men, who are generally heavier than women, overcome the protective cushion of the air bag and strike the steering wheel more readily.

Ferguson et al offered some evidence that air bags were more effective for longer vehicles. ${ }^{1}$ Kahane exam- 


\section{What is already known on this topic}

Studies have estimated that driver air bags reduce the risk of death in a road vehicle crash by $10-14 \%$

These studies disagree as to whether benefit is greater for drivers wearing a seat belt or for unbelted drivers

\section{What this study adds}

Having an air bag was associated with an $8 \%$ reduction in the risk of death, whether the driver was belted or not

The reduction in risk was greater for women $(12 \%)$ than for men $(6 \%)$

Seat belts provided much greater protection, with seat belt use reducing the risk of death by $65 \%$ (or by $68 \%$ in combination with an air bag)

ined vehicle weight as a possible effect modifier, and found no clear variation in effects by weight. ${ }^{2}$ We found no evidence of effect modification by vehicle weight or length.

\section{Conclusions}

Driver air bags offered relatively little benefit in road vehicle crashes compared with seat belts. Air bags reduced the risk of death by about $8 \%$, whereas seat belts reduced the risk of death by $65 \%$. (This estimate for seat belts is similar to an estimate of $62 \%(95 \%$ confidence interval $60 \%$ to $64 \%$ ) that two of us reported in a study using similar methods. ${ }^{15}$ ) Using a seat belt and having an air bag reduced the risk of death by $68 \%$.

We thank the Highway Loss Data Institute (Arlington, VA) for their Vindicator software and Christopher Mack for programming help with the FARS data files.

Contributors: PC initiated and designed the study, performed the data analysis, and wrote the first draft. BM provided advice about the statistical methods. All authors helped interpret the results and revise the manuscript. PC is guarantor for the study.

Funding: This study was supported by grants R49/ CCR002570 and R49/CCR019477-01 from the Centers for Disease Control and Prevention, Atlanta, GA.

Competing interests: None declared.

1 Ferguson SA, Lund AK, Greene MA. Driver fatalities in 1985-1994 air bag cars. Arlington, VA: Insurance Institute for Highway Safety, 1995.

2 Kahane CJ. Fatality reduction by air bags: analysis of accident data through early 1996. DOT Report Number HS 808 470. Washington, DC: National Highway Traffic Safety Administration, 1996.

3 Rothman KJ, Greenland S. Modern epidemiology. 2nd ed. Philadelphia: Lippincott-Raven, 1998:76-7, 283-5.

4 Cummings P, Koepsell TD, Roberts I. Case-control studies in injury research. In: Rivara FP, Cummings P, Koepsell TD, Grossman DC, Maie RV, eds. Injury control: a guide to research and program evaluation. New York, NY: Cambridge University Press, 2001:139-56.

5 Cumminos P, McKnight B, Weiss NS. Matched-pair cohort methods in traffic crash research. Accid Anal Prev (in press).

6 Traffic safety facts 1998: a compilation of motor vehicle crash data from the Fatality Analysis Reporting System and the General Estimates System. Washington, DC: National Highway Traffic Safety Administration, 1999.

7 Evans L. Double pair comparison-a new method to determine how occupant characteristics affect fatality risk in traffic crashes. Accid Anal Prev 1986;18:217-27.

8 Greenland S. Modelling risk ratios from matched cohort data: an estimating equation approach. Appl Stat 1994;43:223-32.

9 Vindicator 2001-Release No 1. Arlington, VA: Highway Loss Data Institute, 2001.

10 Hardin J, Hilbe J. Generalized linear models and extensions. College Station, TX: Stata Press, 2001:196-7.

11 Greenland S. Dose-response and trend analysis in epidemiology: alternatives to categorical analysis. Epidemiology 1995;6:356-65.

12 Long JS. Regression models for categorical and limited dependent variables. Thousand Oaks, CA: SAGE Publications, 1997:87-9, 93-7.

13 Stata Statistical Software: Release 7.0. College Station, TX: Stata Corporation, 2000.

14 Hinch J, Hollowell WT, Kanianthra J, Evans WD, Klein T, Longthorne A et al. Air bag technology in light passenger vehicles. Washington, DC: National Highway Traffic Safety Administration, 1999.

15 Cummings P, Wells JD, Rivara FP. Estimating seat belt effectiveness using matched-pair cohort methods. Accid Anal Prev (in press).

16 Zador PL, Ciccone MA. Automobile driver fatalities in frontal impacts: air bags compared with manual belts. Am J Public Health 1993;83:661-6.

17 Lund AK, Ferguson SA. Driver fatalities in 1985-1993 cars with airbags. $J$ Trauma 1995;38:469-75.

18 Kleinberger M, Summers L. Mechanisms of injuries for adults and children resulting from airbag interaction. In: 41st annual proceedings, Orlando, FL, 1997. Vol 41. Barrington, IL: Association for the Advancement of Automotive Medicine, 1997:405-20.

(Accepted 19 April 2002)

\section{A memorable patient}

\section{A lie softly spoken}

She was a vivid patchwork of red and black from ankles to neck, surrounded by a miasma of singed hair and charred flesh. Even from the end of the trolley, the story and outcome were obvious-a cooker fire, a burning nightgown, dripping molten rivulets down her legs and pooling on her feet. She'd been lying for several hours before discovery, and, although conscious on admission to casualty, she was clearly moribund.

Awoken from a deep sleep, I performed on autopilot: wide bore intravenous lines, fluids, intubation-all textbook ATLS stuff. A secondary survey confirmed our first glance impression. The decision was straightforward (she had no relatives, was elderly, and with more than $70 \%$ burns): admit to intensive care, keep comfortable, and allow her to die. Filled with opiate, she died several hours later.

My most meaningful contribution to her care had been to talk softly to her as I prepared to anaesthetise her: "Think of something nice to dream about, we're just going to drift you off to sleep and get you sorted out. You're going to be all right." The lie slipped out easily, effortlessly lubricated by frequent repetition over the years.
Two showers and 24 hours later, I still fancied that I carried the aura of charred flesh with me-shopping, to my sons' nursery school, around my own home. I struggled to imagine her last few awful, pain filled hours, helplessly waiting for discovery.

Immolation is far down the list of good ways to die. Can any of us foresee our own ends, do more than hope and dream for a quiet death in our own beds?

So why write this?

Even in the face of imminent death, maybe especially then, human contact and hand holding are of more value than simple technical skills

Also, I lied to her, and would do so again in similar circumstances. Should I? Would you? Can lying to patients sometimes be the right thing to do? Or does this story illustrate a lingering paternalism and arrogance that doctors may have when dealing with patients? I have no easy answers to those questions, and suspect there aren't any.

Ian Nesbitt consultant in anaesthesia and intensive care, Newcastle upon Tyne 